\title{
Education Modeling for the Common Good
}

FRANCISCO José LEANDRO

Corresponding author: francisco.leandro@usj.edu.mo

Institute for Research on Portuguese Speaking Countries

City University Macau, China

\section{About the author}

Francisco José Leandro is an associate professor of Institute for Research on Portuguese Speaking Countries, City University of Macau, China. In 2005, he received his Master's Degree and in 2010, his Ph.D. in Political Science and International Relations from the Catholic University of Portugal. In 2017, he successfully concluded a post-doctoral program at University of Macau-China in geopolitical security studies. He has a special interest in Education Sciences, International Law and Geopolitics.

\section{Abstract}

This article proposes a possible model of education for the common good with the application of technologies in the globalized era. It also aims to answer the question of why we have to combine emotional intelligence and ethics to sustain such a model. Education is the engine of evolution without revolutions, as it presents the newness of positive life. The future of education lies in guiding people to act, with others, for the right reasons, and with ethics as the beacon of human dignity. This article is dedicated to act as seeds and agents of positive and peaceful transformation in education.

Keywords:Education, Common good, Modeling, Ethics and moral leadership 


\section{Introduction}

Educational models are a central issue for all societies. By regarding education as an end in itself, we recognize knowledge to be one of the ultimate values in our globalized world. According to John Naisbitt (2017), education is seen more and more as an economic priority in a world dominated by interdependency and uncertainty. The current digital age has brought with it a sense of ease and immediacy, which is promoting a developing form of nihilism. Education should not be conducted with an attitude to reject values and deny all religious and moral principles, with a belief that life is meaningless. Education, in the age of technology, appears to foster unpredictability and a sort of hyper-individualism. When one desires to create something, the first step is to recognize the relevance of and the opportunity for the proposed contribution. Education is no longer associated with a specific period in life, or only with youth. Education is a lifelong process. However, one may ask what education is, and what a well-educated being is. Education is primarily about developing an intellectual and rational curiosity, which leads individuals to develop transformational skills and moral standpoints. Consequently, an educated being is one capable of apprehending a particular reality more clearly than a layman, and one who is skilled enough to involve others in making responsible decisions to transform reality according to a specific conception of the good. The word 'layman' is used in the sense of an individual without specialized knowledge in a particular subject or who is not an expert in a specific subject matter. Harari (2017) seemed to question the ability of future generations to make informed and responsible decisions, in light of artificial intelligence. We truly believe that education is a process which leads individuals to apprehend reality, to acquire an array of skills, and to make the best possible decisions.

Education significantly influences an individual's future options and, to a certain extent, it shapes our collective destiny. Education is a landmark of our current existence and a vital tool to prepare for the future. Education is the means for transforming the Hobbesian state of nature, not by replacing empty minds, but by promoting the Aristotelian vision of human flourishing. Education is the engine of evolution without revolutions. It is not merely acquiring skills; it must facilitate the identification of values and responsible criticism to promote moral self-determination. Nicholas Walton (2017, p.8) observed,

"Education will be less about learning information and more about analyzing and using data. Content knowledge is becoming a commodity... The world no longer cares about what students know, but what they can do with what they know. To this end, we have identified the following types of skills current students will need to flourish in the world as adults: Interdisciplinary skills; Creative and analytical skills; Entrepreneurial skills; Leadership skills; Digital and technical skills; and Global awareness and civic education."

The primary role of education should be the development of respectable individuals, responsible citizens, and skilled producers and innovators. To a certain extent, the purpose of education is to facilitate the pursuit of individual and collective happiness, in the context of a positive life. Education should craft Stuart Mill's "progressive being" capable of being improved through free and equal discussion (2008, p. 15). Education should be a process organized not according to a certain pre-designated rationale, but it should be organized to bring human beings nearer to the best they can be (Mills, 2008, p. 82).

Journal of Management and Training for Industries, Vol.5, No.2, 2018 
This paper draws from the ethics of positive pluralism and aims to identify criteria to develop an educational model for the future, to self-adjust to the imminent reality and to promote the common good. Our starting question is: why should we combine emotional intelligence and ethics to sustain a model of education for the common good?

\section{What is educational modeling?}

Models attempt to depict an objective reality in a simplified way and to describe only those parts of reality which are considered important - those congruent with the purpose of the model. A model is like a map. A theoretical educational model is a simplified map of concepts; the act of abstracting eliminates certain details to focus on essential factors. It, therefore, represents selected features to clarify a complex reality. Modeling represents an assumed compromise between generalization and simplification to obtain a certain level of accuracy, to offer the possibility of expansion and to facilitate prognoses. However, modeling runs the risk of oversimplification, leading to mistaken representation for reality and premature or inaccurate conclusions.

Education models are currently dominated by lessons learned from the past, as these are the only, or, perhaps, the best, social capital available as a foundation for future models. We adopt here the concept of social capital put forward by Bourdieu and Wacquant (1992, p. 119), "the sum of the resources, actual or virtual, that accrue to an individual or a group by virtue of possessing a durable network of more or less institutionalized relationships of mutual acquaintance and recognition". We should therefore consider what type of societies we wish to construct, and then to consider what education model will achieve that development. We have to anticipate the future without referencing a mathematical model of prediction, but rather with a constructivist state of mind. The central aspect of future societies seems to be globalization and all the complex challenges that this brings. Therefore, future societies will also be digital, technologically dominated, driven by a certain degree of inter-dependency, shaped by an enduring multiculturalism, disturbed by constant uncertainty and troubled by escalation and emergencies. The future generations are called as "digital natives by Nicholas Walton (2017, p. 16).

In addition, advances in technology shorten and compress our perception of time, and this will deeply affect us all. Technical information will be accessible to almost everyone. As a direct consequence, moral education will stand out as a crucial attribute, so that public good and public trust will not be perceived as a chimera. Moral education calls for more than mere access to information; it requires reflection and autonomy. The real value of an exercise, such as pondering educational modeling, rests with the process rather than the conclusions. In fact, modeling will always be an abridgement, incapable of providing an accurate answer. However, in this case, our model allows us to highlight the importance of combining three types of skills to be developed: technical, relational and ethical.

Consequently, the design of our educational model envisages three educational dimensions: Us \& the World, Us \& Others and Us \& Us. These three educational dimensions extend the flexibility of professional roles, because models in general are open to a process of unlimited adaptation, in which the learners identify 
and explore their own options based on intelligent emotions and individual focus of interests. Educational modeling is an exercise for identifying the structuring pillars of education, which will bring about the common good through attempts and corrections, and enhance the ability to make free and educated choices. Finally, an educational model for the future must address the idea of learning for a sustainable future as recommended by the Program for the United Nations Decade of Education for Sustainable Development (UNESCO, 2005, 2010). We need to learn from the diverse complexity of learning with no preconditions. As Spencer (2014) stated, "Teaching is leading students into a situation [from] which they can only escape by thinking". By actively building options and making informed decisions, it differentiates the Homo habilis from the Homo sapiens.

\section{What do we understand by 'the common good'?}

Next, we have to define "the common good". Current common good theory includes a dominant reference to social and economic welfare. In non-Western moral and political thought, specifically in Confucian philosophy, the idea of the common good has been associated with the dependency between the flourishing of the individual and the flourishing of the group (Bloom, 2009). In modern Islamic political thought, the common good is often used to depict a set of foundational principles of tolerance, equity and a methodical sense of citizenship. By the same token, John Rawls (2003), with his perception of justice as fairness of opportunities, defined the common good as "certain general conditions that are ... equally to everyone's advantage". The Catholic tradition defines it as "the sum of those conditions of social life which allow social groups and their individual members relatively thorough and ready access to their own fulfilment" (Manuel Velasquez, et al., 1992). The position of Saint Thomas Aquinas (1225-1274, questions 1, 2. 4 and 90) is particularly remarkable: he described the common good as a mutual entailment or consequence and defined it as the purpose of law and the pursuit of governments. Likewise, Jean-Jacques Rousseau (1947), in The Social Contract (Book IV, Chapter 1, Paragraphs 1 and 2), made an interesting distinction between general will and the will of all. His aim was to stress that the latter is merely the sum of each individual's desires, while the former is directed towards common preservation and general well-being. Along similar lines, F. Rosamond Shields (1913-1914, pp. 274-290), summarized the common good as the "free and faithful community of all mankind, wherein the individuals should indeed die to their own natural life, but should also enjoy a newness of positive life". Martin Rhonheimer (2013) argued that the common good "includes a set of socially shared values which morally legitimatize both the basic political structure of constitutional democracy and the outcome of the political process shaped by its legal and political institutions. The basic legal and political institutions of constitutional democracy are themselves a common good, not only for individuals but also for social communities. They make cooperation in peace, liberty and justice possible".

In 2015, UNESCO published a book entitled "R hinking Education: Towards a Global Common Good?". The book called for a new model of education with sustainable development as a central concern and reaffirmed the need for a humanistic approach to education. The book (p.72) emphasized the idea of education and knowledge as global common goods (UNSCO, 2015, p. 77-78). It quoted the definition 
given by Deneulin and Townsend (2007) and reconfirmed that the common good is highlighted by three elements: (1) the goods that humans intrinsically share in common; (2) the communication people share with each other, regarding values, civic virtues and a sense of justice; (3) the solidarity of persons that is more than the good of individuals in the aggregate. It is indeed the good of being a community, and the good apprehended in mutual relationships, in and through which human beings achieve their wellbeing. The common good is, therefore, inherent in the relationships that exist among the members of a society linked together in a collective endeavor.

UNESCO went on to say that the principle of education as a public good should be preserved, but asked, "What is meant by the common good?":

"Can that only be defined with regard to the diversity of contexts and concepts of wellbeing and common life? Diverse communities will, therefore, have different understandings of the specific context of common good. The notion of common good goes beyond the instrumental concept of public good where human well-being is framed by individualistic socioeconomic theory. From a 'common good' perspective, it is not only the 'good life' of individuals that matters, but also the goodness of life that humans hold in common $\cdots$. The concept emphasises the participatory process, which is a common good in itself."

Morgan and I. White (2014, pp.38-41) pointed out that in re-visioning education in a new global context, we should reconsider not only the purposes of education but also how learning is organized. In light of the diversification of partnerships and the blurring of boundaries between public and private, we have to/should rethink the principles that guide educational governance and, in particular, the normative principle of education as a public good and how this should be understood in the changing context of society, state and market.

All in all, it seems that the concept of common good changes over time, according to different communities and contexts, as a result of social and individual interactions. It is an ongoing, dynamic and participatory process of identifying what individuals of a certain community value, in which diverse private and public actors are involved in. Actors have their natural expectations of well-being and self-fulfillment as a reference, along with what they share intrinsically as a sort of bonded fellowship in the pursuit of a positive collective endeavor. In other words, the common good is the goodness of life that humans hold as individuals, alongside what they recognize as having in common as a community of shared endeavors. The common good is associated with collective transformational conditions in the pursuit of happiness. It also serves to legitimize social-political processes, bringing stability and enduring capacities. Consequently, we must strive for an educational model that builds on dynamic, inclusive and plural ideas of the common good, where its sum represents the global common goods.

\section{The three components of the proposed educational model}

Based on the above idea of the common good, Fig. $⿴$ is a visual representation of the proposed educational model, where the dotted lines represent the need for openness and ongoing adaptation. The model combines three educational fields: intuitive reality construction (in the context of a student's field of studies), positive 


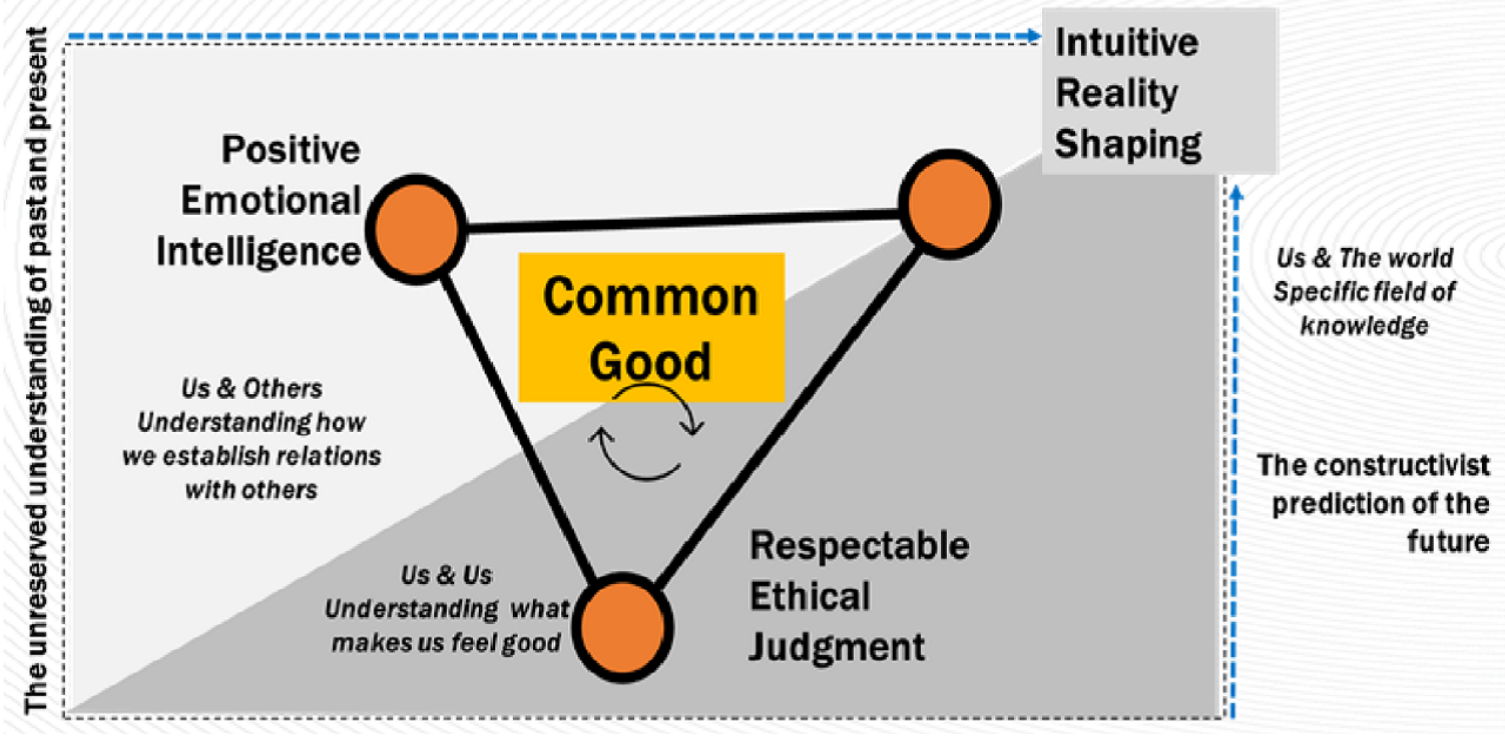

Fig. 1 Proposed Educational Model

emotional intelligence and ethical judgment. Predicting the future acknowledges the great impact of technology, as pointed out in The Economist (May 31, 2017). Predicting the future stands for the process to see what lies ahead in technology, and to look to the past, the present and the imagined futures of science fiction. Prediction, however, is different from projection. When we use the word "prediction", we do not envisage forecasting a future situation based on a trend or previous development. On the contrary, we wish to comprehensively anticipate a vision of the future based on how we understand it today, regardless of past indicators. In each of the three educational fields, referent subjects are also mentioned, serving as guidelines to deepen reflection and bring about other interactions to improve the model. An educational model looks for an understanding of the past, and awareness of the present, as a gateway to anticipate the future, based on a circumstantial notion of the common good.

\section{Intuitive Reality Construction - Us \& The World - In a Specific Field of Knowledge}

In this first sector, we focus on specialization, which refers to the development of technical skills and topics such as scientific research, technology, globalization, innovation, creativity and creative writing. Any educational model should develop a natural attitude towards intellectual curiosity, as Ordine notes (2017). The development of individual natural intellectual curiosity as a value per se appears to be a driving force of education. It has the potential to compel individuals to grasp the current world more clearly and create a path to future reality-shaping. Alan Dershowitz (1993), in his introduction to John Stuart Mill's "On Liberty \& Utilitarianism" (1859), wrote, "Truth is not a piece of matter or a unit of energy that will survive pummelling and emerge unscathed in one form or another at one time or another. It is a fragile and ethereal aspiration, easily buried, difficult to retrieve, and capable of being lost forever." The Millennium Project 
(2006-2007) conducted the study on Education and Learning Possibilities by the Year 2030. At a certain point, the study asserts that the teaching of morals and the routine assessment of characteristics other than intelligence (e.g. emotional intelligence) will be commonplace. The study emphasized the need to learn how to learn, and indicated the types of skills the future will require - not merely the acquisition of new facts, but the capacity to discard the unnecessary and to transform useful information into effective and productive realities. It is also necessary to integrate global awareness with local involvement. The flow of ideas worldwide due to new technological conditions will be significant. While we should develop open mindsets, they have to be combined with individual transformational skills to select intelligently what represents the essential in each being. An accurate awareness of reality is the basis of individual knowledge, but the focus must be set on research processes rather than the collection of information. Factors including uncertainty, unpredictability, robotization, mass customization and time compression, all call for an educational model that values creativity and stimulates innovation, fosters sustainability and develops reasoning above memorization, replication, imitation and duplication. Walton (2017, p.14) refered to "a constellation of skills". In the future, education will focus more on principles, rationale and processes, and less on details, formulas and standards. On the one hand, creativity is about unleashing the potential of the mind to conceive new ideas. Creativity is difficult to measure; it is subjective and self-rewarding. On the other hand, innovation is a measurable process of inducing change which stems from creative processes. The combination of a rational understanding of challenges, creativity and innovation has the potential to develop a positive attitude in individuals and, therefore, discovers a natural affinity towards design thinking. We have to be capable of not only finding what we need but also capable of creating pioneering solutions with what we have.

\section{Positive Emotional Intelligence - Us \& Others - Understanding How We Establish Relations with Others}

In this second sector, we discuss the development of relational skills and topics, such as languages and culture, communication in a globalized world, leadership, stress management, resilience and conflict resolution. Furnham (2012, p. 5) talked about "multiple bits of intelligence" and listed fourteen different types of intelligence: (1) analytical (Sternberg, 1997), (2) bodily-kinesthetic (Gardner, 1999); (3) creative (Sternberg, 1997); (4) emotional (Salovey and Mayer, 1990); (5) interpersonal (Gardner, 1999); (6) intrapersonal (Gardner, 1999); (7) mathematical (Gardner, 1999); (8) musical (Gardner, 1999); (9) naturalistic (Gardner, 1999); (10) practical (Sternberg, 1997); (11) Sexual (Conrad and Milburn 2001); (12) spatial (Gardner, 1999); (13) spiritual (Emmons, 2000); (14) verbal (Gardner, 1999). Others, such as Sternberg (1997) and Gardner (1999), defined intelligence as "the ability to solve problems or to create products that are valued within one or more cultural settings" (Gardner, 1999, p. 11) and specified seven bits of intelligence. This statement envisages that positive emotional intelligence will be a driving force in future educational models. Emotional intelligence is regarded as a social relational competence (Mackintosh, 1998). Furnham (2012, pp. 7-8) explained that emotional intelligence plays a dominant role in our life achievements, and that it is 
clearly based on self vs others, as well as emotional awareness vs emotional management. He identified the following components of emotional intelligence in individuals/humans (Furnham 2012, p. 10):

- Adaptability (flexible and willing to adapt to new conditions);

- Assertiveness (forthright, frank and willing to stand up for their rights);

- Emotion expression (capable of communicating their feelings to others);

- Emotion management (capable of influencing other people's feelings);

- Emotion perception (self and others - clear about their own and other people's feelings);

- Emotion regulation (capable of controlling their emotions);

- Impulsiveness (reflective and less likely to give in to their urges);

- Relationship skills (capable of having fulfilling personal relationships);

- Self-esteem (successful and self-confident);

- Self-motivation (driven and unlikely to give up in the face of adversity);

- Social competence (accomplished networkers with excellent social skills);

- Stress management (capable of withstanding pressure and regulating stress);

- Trait empathy (capable of seeing someone else's perspective);

- Trait happiness (cheerful and satisfied with their lives);

- Trait optimism (confident and likely to 'look on the bright side of life').

Future educational models will most likely be based on the development of four categories of emotional intelligence: self-awareness, self-management, social awareness and relationship management. Positive emotional intelligence combines the ability to self-manage with relational management to bring about a positive transformation of the circumstantial common good. That is why self-management deserves particular emphasis. Cynda Rushton (2016) defined moral resilience as the capacity of an individual to sustain or restore his/her integrity in response to moral complexity, confusion, distress or setbacks. Moral resilience has also been described as "a distinct sense that life is meaningful under every condition" (Lützén and Ewalds-Kvist, 2013) and by Monteverde (2013) as the "ability to manage moral stressors".

In relational management, leadership skills merit specific emphasis. Leadership is the ability to motivate others to do things that they otherwise would not consider doing. It also includes tasks in the manner intended by the leader in terms of production and expected results. Education has to be connected to the real world; along these lines, Nicholas Walton (2017, p. 4) called for the "classroom walls to be broken down (adapted)". An important aspect of leadership skills is a command of English and at least two more languages (true multilingualism), and an effective semiotics interpersonal communication. The true multilingualism refers to the ability to command English and two other languages from different language families (The Millennium Project, 2006-2007). A particular area of immediate improvement could be to give each infant the opportunity to develop at least two languages in their first two years of life. True multilingualism has many other benefits for the development of individuals, including social benefits related to the early recognition of different cultures. This concept is opposed to the much more difficult and less useful, but prevalent path of learning other languages after the "infant window" has closed. We should be capable of 
identifying what we need and capable of creating pioneering solutions involving the positive motivation of others.

\section{Ethical Judgement - Us \& Us - Understanding What Makes Us Feel Good}

In this third sector, we include the development of ethical skills and topics such as the ethics of pluralism, gender, thinking and reasoning, art and criticism, and citizenship. Ethics is always at the center of any educational rationale, simply because it is the last moral frontier that keeps humans from the unacceptable, from chaos and savagery. Nicholas Walton (2017, p. 15) emphasized the need to educate for an "ethical future". Ethics grows on carefully-considered free choices, which draws the line between what can be compromised and what is unacceptable. "A wise (or virtuous) person is one who knows what is good and spontaneously does it" (Varela, 1999, p. 4). Ethics is more than just identifying the good and the bad; it stands for fundamental moral commitments and allows for the establishment of criteria by which people dispute about moral dilemmas. Johan Galtung (1969, p. 168) stated that "violence is present when human beings are being influenced so that their somatic and mental realizations are below their potential realizations". Ethics is a means to defeating moral violence. As John Rawls (2003) suggested, the notion of good should be associated with the project for personal life, self-respect and the attitude towards those who are least benefited. It should also pay attentional to the need for social equity, as a quest for congruence between "the good" and justice. Therefore, any educational model for the future must offer pluralistic moral options and the ability to combine value judgment with the speech of act. It is driven by a growing moral trend in which we treasure what we experience as fulfilling, instead of what we possess materially. Learning ethics, as one of the components of the model, as a step to recognize a system of values freely, is fundamental to acquiring the moral skills. Those skills can be developed into a sort of moral leadership involving a power relationship. A powerful moral relationship among individuals are developed based on shared values, moral inspiration, positive interpersonal bonds, voluntary adherence and free moral willingness which are committed to the transformational process. Gini (1997, p. 324) asserted that "leadership is a power and value-laden relationship between leaders and followers/constituents who intend real change(s) that reflect their mutual purpose(s) and goal(s)". Moral leadership cannot be taught. Ethics represents the struggle to get closer to an individual authenticity, to the true meaning of values; ethics assumes the responsibility to deliver and holds the potential to galvanize the others' will. It is driven by the purpose to contribute to common good.

The categorical notion of pluralism put forward by Hinman (2013) stresses the importance of the limits and tolerance to diversity, the rejection of racism and the fight against chauvinism. It also implies that the unacceptability of xenophobia and the stand against indifference, bigotry and extremism should be taken into accounting when discussing the issue. Pluralism flourishes on a clear understanding of the implications of being different - namely in relation to culture, gender, race and ethnicity — and on a precise identification of the limits of what is tolerable. Both vices and moral dependency are highly prominent in our present 
world of immediacy, where the current moment is considered the most important. However, this understating callously diminishes human potential. Education should provide an avenue to decrease moral dependency and profile consistently responsible and morally educated autonomy because these values are devices for crafting the common good. The byproducts of the digital era are particularly disturbing. This era offers an increasing array of online electronic devices that can cultivate a false sense of security since all forms of extreme violence are being curbed and convey a make-believe virtual reality. Additionally, the digital world offers an impoverished form of networking and therefore a poor understanding of real human bonds. Zygmunt Bauman (2012) explained that the digital era is transforming the notion of networking by attacking the core of the sense of belonging, where the community prevails over the individual and reduces the perceived bounds by providing easiness of disconnecting and connecting with another network. He used the example of "Facebook friends", where the biggest attraction seems to be the possibility of disconnecting without any explanation or confrontation. Zygmunt Bauman (2012) identified the compromise between security and liberty as the essence of moral values, and therefore as the way to achieve dignity in human life. However, the proportion of the former, which should be sacrificed to obtain the latter and to standardize the path to human dignity, has not yet been discovered. This is certainly part of the self-discovery in the future educational model. Good moral judgment in cross-cultural affairs facilitates moral acceptance. Human dignity is a moral standard that combines conservative discipline (towards moral commitments), transformational responsibility (towards the self and the community of others), foundational respect (towards the self and the legacy of former and for future generations) and amiable self-love as the purpose of life. We should be capable of finding what we need to create pioneering solutions involving the positive motivation of others, for the right moral reasons.

\section{Conclusions}

Why should we combine emotional intelligence and ethics to sustain the model of education for the common good? Karl Popper (1966) fought strongly against historicism, arguing that when we know that reality will happen in a certain way, regardless of our personal and collective efforts, we do not feel compelled to construct it as we believe it should be. Education is an industry of ideas and therefore the definitive avenue for facilitating the transition into the future. If the common good is a dynamic and plural concept; if the common good is a result of multi-level societal interactions; if the identification of the common good combines different types of skills with a rewarding vision; if the common good means equity and standing against evil; and if the common good calls for justice and good governance, then we need an open, self-learning educational model, which enables us to track the prediction of the contingency concept of the common good, with ethics as the beacon of human dignity. We need an educational model that helps individuals develop skills to intuitively grasp reality, as an exercise of natural intellectual curiosity and not as a carved-in-stone formula. As Karl Popper stated (1966), ideas should not be treated as perishable commodities. More importantly, we need an educational model that induces positive living (in the sense of personal fulfillment), merging the apprehension of reality with positive emotional intelligence and ethical judgment. The model we envisage balances the allocation of intuitive, reality-shaping resources and the sum of positive emotional 
intelligence with ethical judgment. Intuitive reality shaping alone will not ensure an ability to understand the common good, since it does not address the self and others. This is why moral leadership implies serving others according to a certain notion of the common good. As Nicholas Walton (2017, p. 18) observed that "teachers are the ultimate resource" for constructing and applying any education model. Above all, our future model combines the enhancement of moral and transformational autonomy, based on a cultivated, self-portrayed reality nurtured by education. This educational model for the common good leads people to act, with others, for the right reasons, with ethics as the beacon of dignity.

\section{References}

Aquinas, T., 1225-1274. "Summa Theologiae", Questions 1, 2, 4 and 90.

Bauman, Z., 2012. "Vivemos numa multidão de solitários", retrieved on June 2017, from https://www. youtube.com/watch?v=LcHTeDNIarU.

Bloom, I. 2009. Mencius. New York, USA: Columbia University Press.

Bourdieu, P. and Wacquant, L. P. D., 1992. An Invitation to Reflexive Sociology. Chicago, USA: University of Chicago Press.

Conrad, S. and Milburn, M., 2001. Sexual Intelligence: The Groundbreaking Study That Shows You How to Boost Your "Sex IQ" and Gain Greater Sexual Satisfaction. London, UK: Crown.

Deneulin, S. and Townsend, N., 2007. "Public Goods, Global Public Goods and the Common Good". International Journal of Social Economics, Vol. 34 (1-2), pp. 19-36.

Emmons, R. A., 2000. "Spirituality and Intelligence: Problems and Prospects", The International Journal for the Psychology of Religion, Vol. 10, Issue 1, pp. 57-64.

Furnham, Adrian, 2012. "Emotional Intelligence - New Perspectives and Applications", Research Department of Clinical, Educational and Health Psychology, University College London, UK, retrieved on July 3, 2017, from https://www.researchgate.net/publication/221923485.

Galtung, J., 1969. "Violence, Peace and Peace research", Journal of Peace Research, Volume 6, Number 3, pp. 167-191.

Gardner, J., 1999. Intelligence Reframed: Multiple Intelligence for the 21st Century. New York, USA: Basic Books.

Gini, A., 1997. "Moral Leadership: An Overview", Journal of Business Ethics, Vol. 16, pp. 323-330.

Harari, Y. N., 2017. Homo Deus: A Brief History of Tomorrow. London, UK: HarperCollins.

Hinman, L. M., 2013. Ethics: A Pluralistic Approach to Moral Theory (5th Edition). New York, USA: Wadsworth.

Lützén, K. and Ewalds-Kvist, B., 2013. "Moral Distress and its Interconnection with Moral Sensitivity and Moral Resilience", Journal of Bioethical Inquiry, Vol. 10, No. 3, pp. 317-324.

Mackintosh, N., 1998. IQ and Human Intelligence. Oxford, UK: Oxford University Press.

Mill, J. S., 2008. On Liberty \& Utilitarianism. New York, USA: Bantam Classic.

Monteverde, S., 2013. Undergraduate Healthcare Ethics Education, Moral Resilience, and the Role of Ethical 
Theories, Nurs Ethics, Vol. 21, No. 4, pp. 385-401.

Morgan, W. J. and White, I., 2014. "Education for Global Development: Reconciling Society, State, and Market", Weiterbildung, Vol. 1, pp. 38-41.

Naisbitt, J., 2017. "Megatrends" - July 29, retrieved in November 2017, from http://www. futuristspeaker.com/business-trends/the-future-of-education/.

Ordine, N. 2017. The Usefulness of the Useless. Philadelphia, USA: Paul Dry Books.

Popper, K., 1966. The Open Society and its Enemies, Vol. I (5th edition). London, UK: Routledge,

Rawls, J., 2003. A Theory of Justice. USA: Harvard University Press.

Rhonheimer, M., 2013. The Common Good of Constitutional Democracy - Essays in Political Philosophy and on Catholic Social Teaching (Murphy W., Ed.). Washington, D.C.: Catholic University of America Press.

Rousseau, Jean-Jacques, 1947. The Social Contract, Book IV. MI, USA: Hafner Press

Rushton, C. H., 2016. "Moral Resilience: A Capacity for Navigating Moral Distress in Critical Care", AACN Advanced Critical Care, Volume 27, Number 1, pp. 111-119, retrieved on July 3, 2017, from nttp: //acc.aacnjournals.org/content/27/1/111.full.pdf+html.

Salovey, P. and Mayer, J. 1990. Emotional Intelligence, Volume 9, Issue 3, pp. 185-211.

Shields, F. R. 1913-1914. "The Notion of a Common Good, Proceedings of the Aristotelian Society", New Series, Vol. 14, Published by Wiley on behalf of The Aristotelian Society, pp. 274-290.

Spencer, A. B., 2014. Teaching with Technology Mini-Talks E-portfolio and Student Clickers. Centre for Teaching and Learning Enhancement, University of Macau, China.

Sternberg, R. J., 1997. Thinking styles. New York, USA: Cambridge University Press.

The Economist (May 31, 2017). "A toolkit for predicting the future", retrieved on June 19, 2017, from https://medium.economist.com/a-toolkit-for-predicting-the-future-2f24757d9699.

The Millennium Project, 2006-2007. "Education and Learning Possibilities by the Year 2030", retrieved on March 31, 2017 from http://www.millennium-project.org/millennium/Education-2030.html.

UNESCO, 2005. "Education for Sustainable Development (ED/PEQ/ESD)". United Nations Decade of Education for Sustainable Development (2005-2014) - Program for the United Nations Decade of Education for Sustainable Development, retrieved on July 5, 2017, from http://www.unesco.org/education/ tlsf/.

UNESCO, 2010. "Programme for the United Nations Decade of Education for Sustainable Development", retrieved in July 2017, from http://www.unesco.org/education/tlsf/.

UNESCO, 2015. Rethinking Education: Towards a Global Common Good?.

Varela, F., 1999. Ethical Know-how: Action, Wisdom, and Cognition. Stanford, CA, USA: Stanford University Press.

Velasquez, M., Andre, C.; Shanks, T. and Meyer, M. J., 1992. "The Common Good", Issues in Ethics, Vol. 5, No. 1 (spring), Markkula Center for Applied Ethics, retrieved on July 2, 2017, from https://www. scu.edu/ethics/ethics-resources/ethical-decision-making/the-common-good/.

Walton, N. 2017. Report Worldwide Educating - For the Future Index: A Benchmark for the Skills of 
Tomorrow. The Economist Intelligence Unit Limited, Yidan Prize Foundation. 